\title{
Habitar corporal-mente el espacio como construcción de heterotopías
}

\section{Living body-mind space as heterotopic construction}

DOI: 10.17981/mod.arq.cuc.18.2.2018.02

Fecha de Envío: 09/09/2018 Fecha de Aceptación: 23/10/2018

\author{
Maria Verónica Machado Penso iD \\ Universidad del Zulia (Venezuela) \\ licirodriguez01@gmail.com
}

Para citar este artículo:

Machado, M. (2018). Habitar corporal-mente el espacio como construcción de heterotopías. MODULO ARQUITECTURA-CUC, vol. 21, no. 1 , pp. 23-62. DOI: 10.17981/mod.arq.cuc.18.2.2018.02

\section{Resumen}

Este trabajo surge del análisis del artículo de Bernhard Waldenfels titulado "Habitar corporalmente el espacio". Es un análisis que discurre por cada uno de sus puntos tratados: el aquí, el allá, el espacio, el tiempo, la interioridad, la exterioridad, la presencialidad, la virtualidad, lo común y lo extraño para indagar en la esencia del habitar de un cuerpo pensante, estudiado desde la perspectiva de las heterotopías propuesta por Michel Foucault y ayudado por la concepción del ser y el habitar y construir en Martín Heidegger. De estas relaciones entre estos tres autores, se concluye que el habitar corporalmente el espacio construye heterotopías y espacios intersticiales donde cuerpo y mente fluyen y confluyen.

Palabras clave: espacio, cuerpo, Waldenfels, heterotopías, Foucault

\begin{abstract}
This work is based on an analysis of the article by Bernhard Waldenfels entitled "Habitar corporalmente el espacio". This analysis addresses each of the concepts treated in the original text: here, there, space, time, interiority, exteriority, presence, virtuality, common and strangeness to inquire about the essence of living in a thinking body. The perspective of the heterotopies proposed by Michel Foucault is applied for this purpose as well as the conception of being, inhabiting and building from Martin Heidegger. From the relationship of the concepts of these three authors, it is concluded that physically inhabiting the space builds heterotopies and interstitial spaces where body and mind flow and converge.
\end{abstract}

Keywords: space, body, Waldenfels, heterotopia, Foucault 


\section{INTRODUCCIÓN}

Habitar el espacio, desde la fenomenología, lo colma de referencias, inferencias y diferencias que identifican al sujeto intrínsecamente con el lugar que habita, pero cuando el sujeto habita un espacio nunca está completamente ahí: una parte está en el aquí que ocupa en el espacio real y otra parte está allá en otro espacio que no puede mezclarse, superponerse, solaparse y fundirse con el ocupado por el aquí. Estos espacios de distinta naturaleza, que no pueden superponerse, solaparse y diluirse los denominó Foucault (1968) como heterotopías:

No vivimos en una especie de vacío, dentro del cual podríamos situar individuos y cosas. No vivimos en una especie de vacío que podría ser coloreado con diversas sombras de luz, vivimos dentro de un sistema de relaciones que define lugares que son irreductibles entre sí y en absoluto superponibles los unos a los otros (...) (p. 46).

Habitar corporal-mente el espacio construye, ya que,

al habitar llegamos, así parece, solamente por medio del construir. Éste, el construir, tiene a aquél, el habitar, como meta (...) así pues el habitar sería en cada caso el fin que preside todo construir. Habitar y construir están el uno con respecto al otro en la relación de fin a medio... Porque construir no es solo medio y camino para el habitar, el construir es en sí mismo ya el habitar (Heidegger, 1994, pp. 127-128).

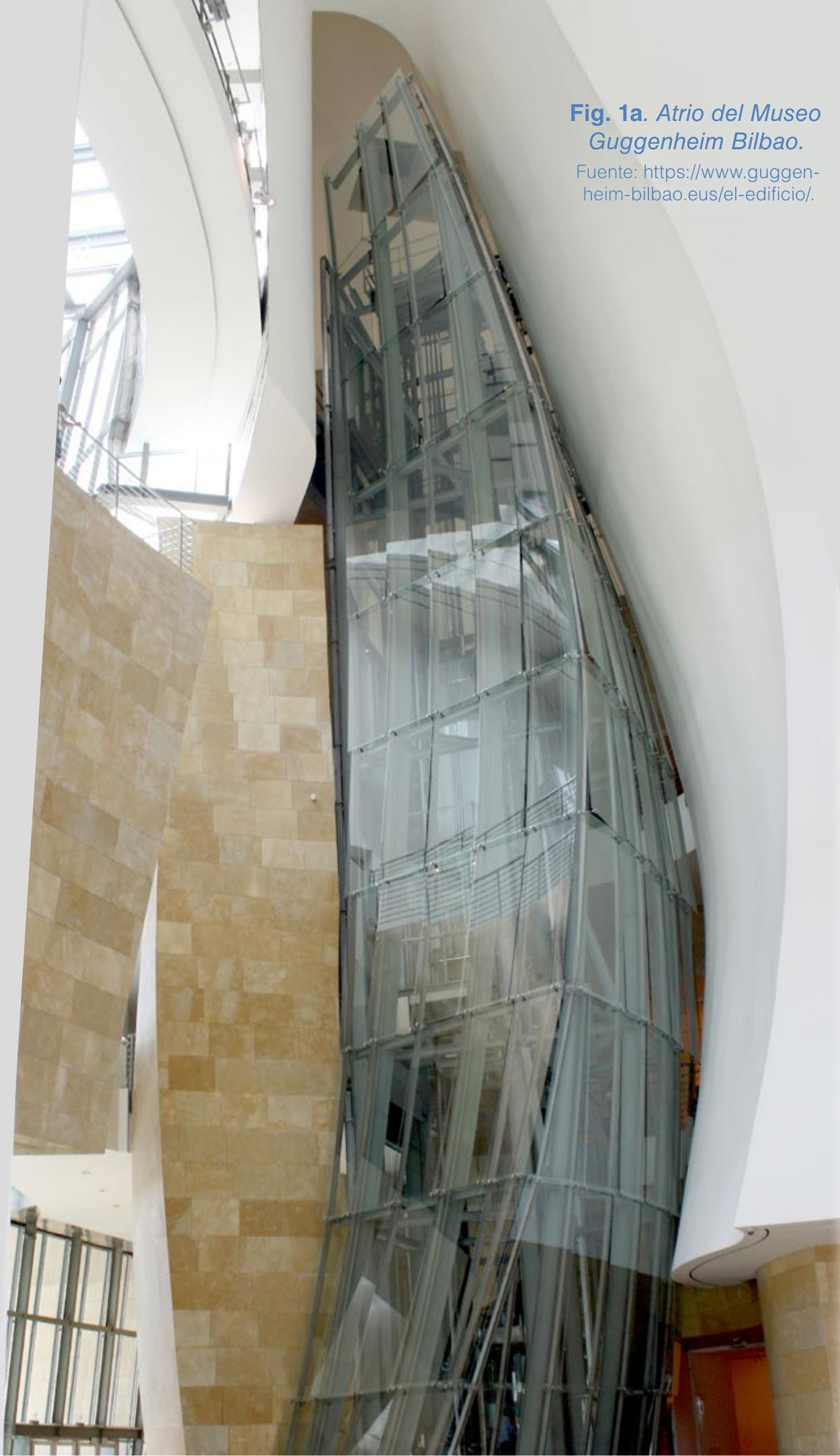


Habitamos corporal-mente ${ }^{1}$ mediante la conciencia corporizada (Merleau-Ponty, 2000), que es más que la suma entre cuerpo y mente, conjugando el cuerpo y la mente en un solo ser que no se considera aisladamente sino contextualmente, "cuerpo que está anudado a un cierto mundo" (Merleau-Ponty, 2000, p. 123).

Merleau-Ponty enuncia una sentencia que nos podría resultar de suyo evidente: el cuerpo no es un objeto. El cuerpo no es un objeto a la manera de partes superpuestas; no somos un alma que se puede escindir del cuerpo, un puro intelecto, junto a un conjunto de músculos y huesos (Costa, 2006, p. 5)

Este enunciado nos interesa en la medida que descubrimos los atributos que definen habitar corporal-mente el espacio.

\footnotetext{
1 Se emplea corporal-mente para enfatizar la idea que tanto cuerpo como mente habitan el espacio en una conjunción que va más allá de una mera sumatoria.
}

Fig. 1b. Atrio del Museo Guggenheim Bilbao.

Fuente: https://www.guggenheim-bilbao.eus/el-edificio/. 
Hoy todo cambia, el entramado de relaciones se vuelve más complejo en lo que el espacio interviene como entorno, lugar, sitio, región, etc., confiriéndole a éste una cualidad, posición, concordancia y discrepancia según la disciplina o punto de vista en que se circunscriba, es decir, que esta diversidad de visiones podría generar valoraciones de espacios: en la sociología, el espacio se asume como medio o ambiente; en la física, el espacio vacío de la modernidad es sustituido por la teoría de la relatividad y la teoría cuántica en el que se incluyen al observador y las lógicas operativas en su concepción; en el lenguaje, el espacio constituye el lugar genuino del habla por la fijación de los signos lingüísticos, la puesta en escena del lenguaje y la génesis de un lugar público; en la historia, el espacio se piensa como un lugar conmemorativo con un nuevo significado, el de la "inscripción de los procesos temporales en el espacio" (Waldenfels, 2004, p. 23) o como huellas que inciden en la memoria (Waldenfels, 2004); en la antropología cultural y etnología, el espacio es el lugar donde la simultaneidad y la sucesión le confiere más peso a los aspectos topológicos que a los aspectos cronológicos; en la comunicación, el espacio tiende a ser amenazado por la ubicuidad,

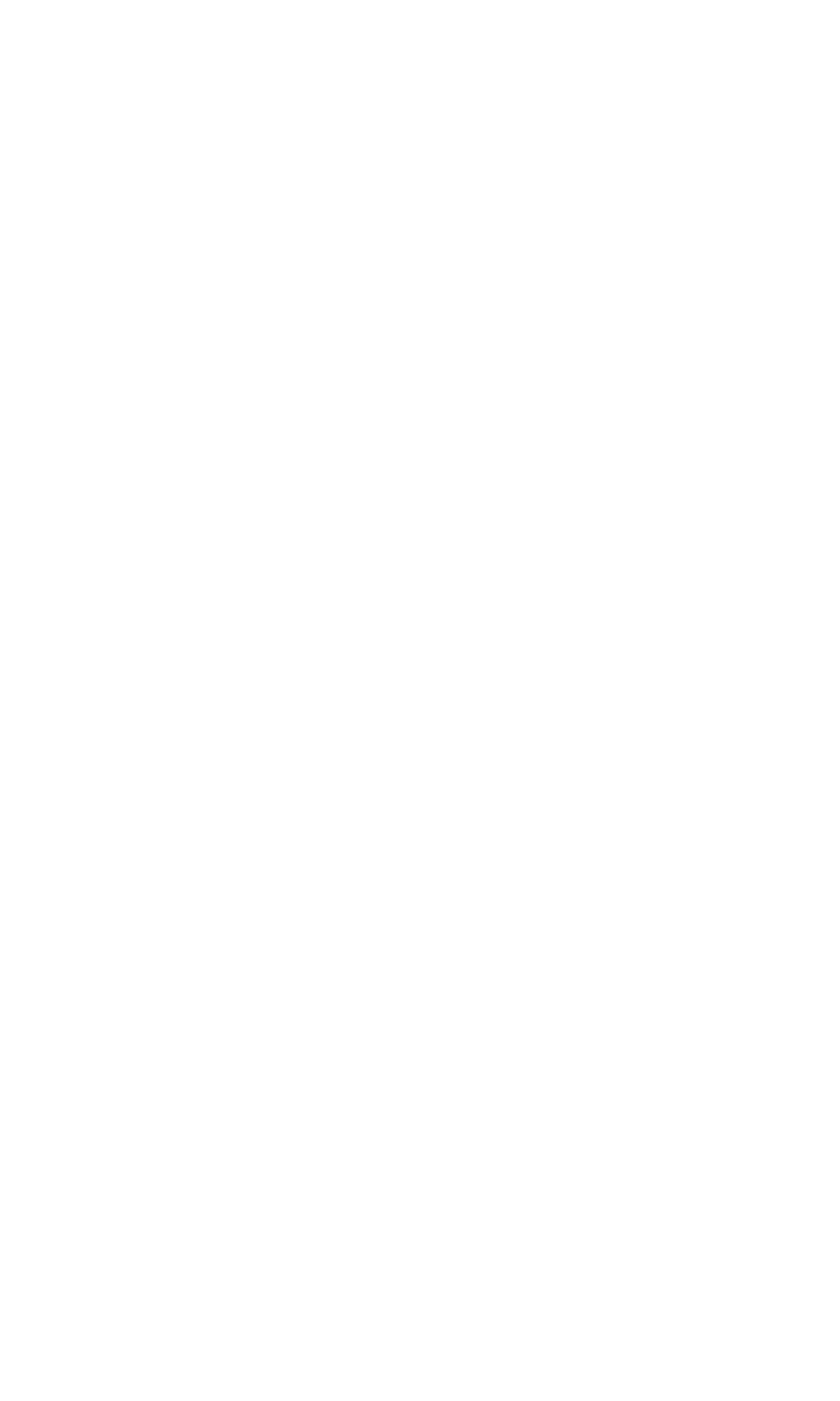




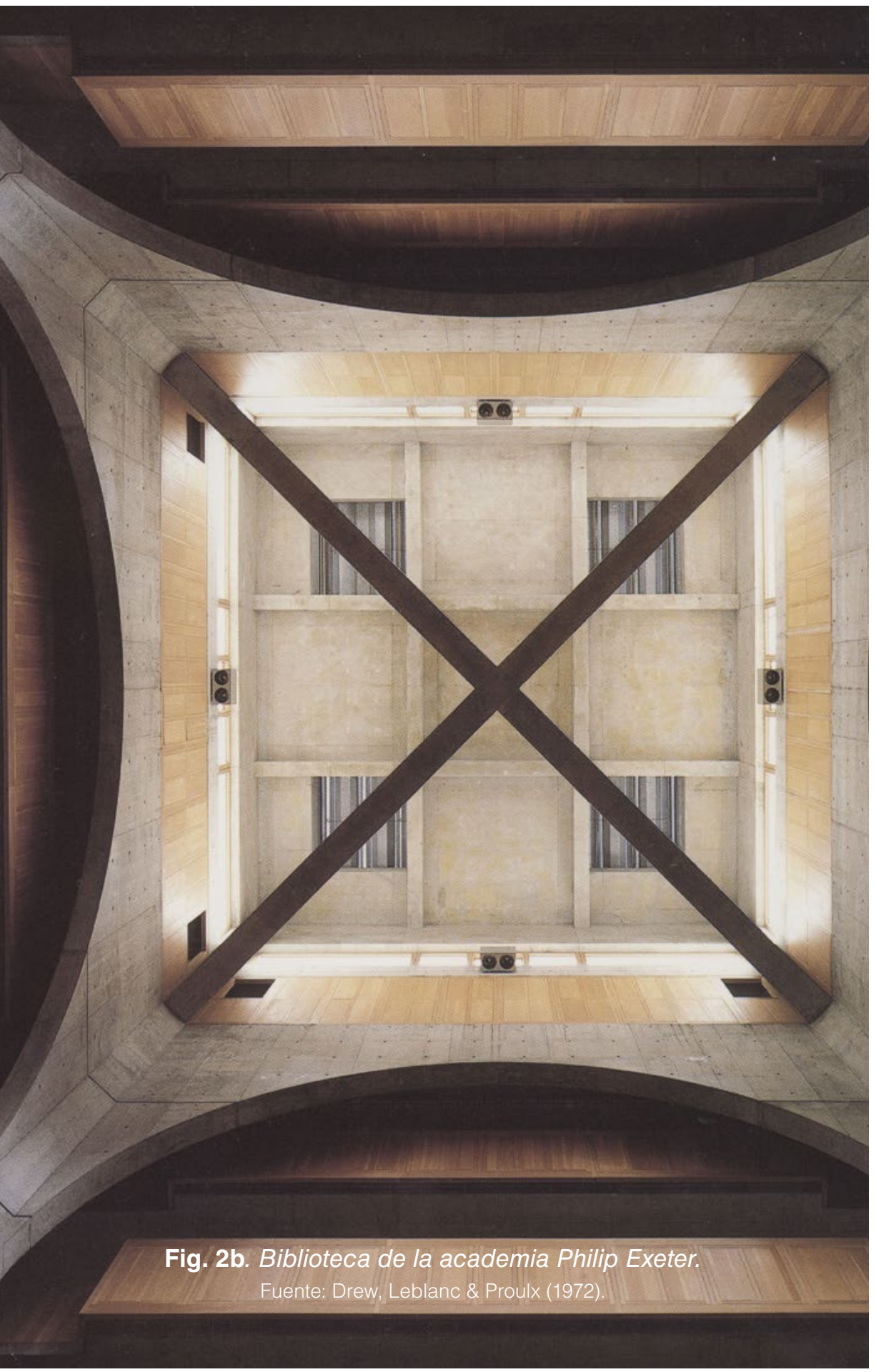

a pesar que la globalización evoca una cuestión de espacialidad; en el arte, el espacio ha sido incluido en la experiencia perceptiva del espectador de la obra, pasando del mero acto de contemplación a obras que se desarrollan como "arte espacial" (ensamblajes, instalaciones, land-art, etc.); en la arquitectura, el espacio gana nuevos aliados al relacionar la arquitectura referencial con la funcional; en las matemáticas, el espacio es entendido como topología; en el psicoanálisis, como tópica; y en la filosofía, desde la fenomenología, se explica el espacio a través de una "fenomenología de lo espacial que parte de la existencia corporal" (Waldenfels, 2004, p. 23), para Husserl "el espacio está inscrito en el horizonte de la percepción y de la corporalidad" (Flores, 2003, p. 265), Merleau-Ponty lo asume como un espacio antropológico que se percibe por la conciencia corporizada, Heidegger lo hace a través del Dasein al cual el espacio le es originario, es así como "Ser y tiempo puede ser leído como Ser y espacio" (Waldenfels, 2004, p. 23), Bachelard define el espacio como topofilia, Foucault lo piensa como heterotopías conformadas por espacios imposibles de superponer y atopías como no lugares, y Whitehead como acontecimientos espaciotemporales. 
Relación entre

especialidad y corporalidad

El estudio del espacio cuestiona los siguientes dos axiomas. el primero asume ayuda a la representación de las cosas, unas con otras y unas fuera de otras (Waldenfels, 2004); y el segundo define al espacio como contenedor que es llenado tanto por los objetos como por
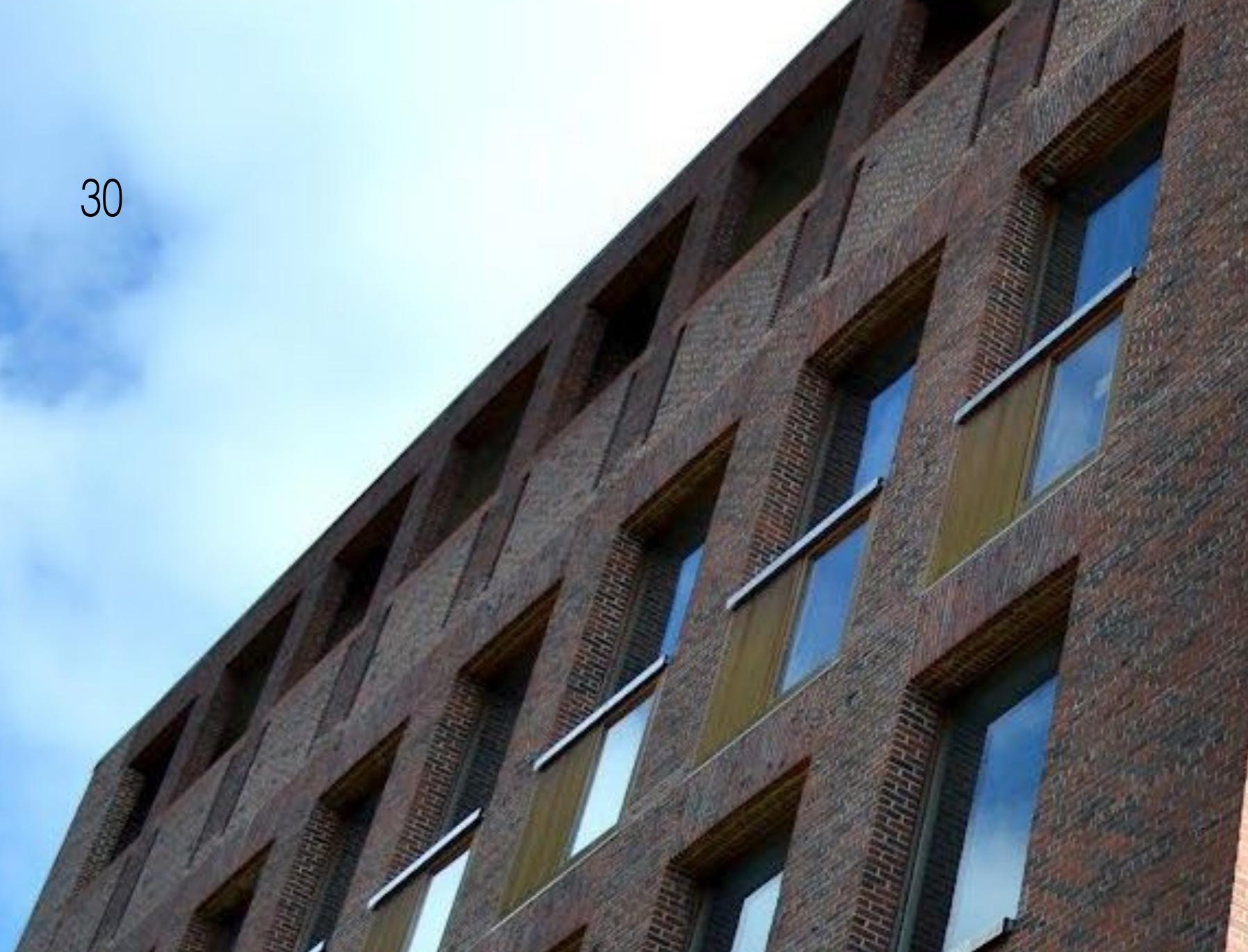

Fig. 2c. Biblioteca de la
academia Philip Exeter.
ante: Drew, Leblanc \& Proulx (1972)
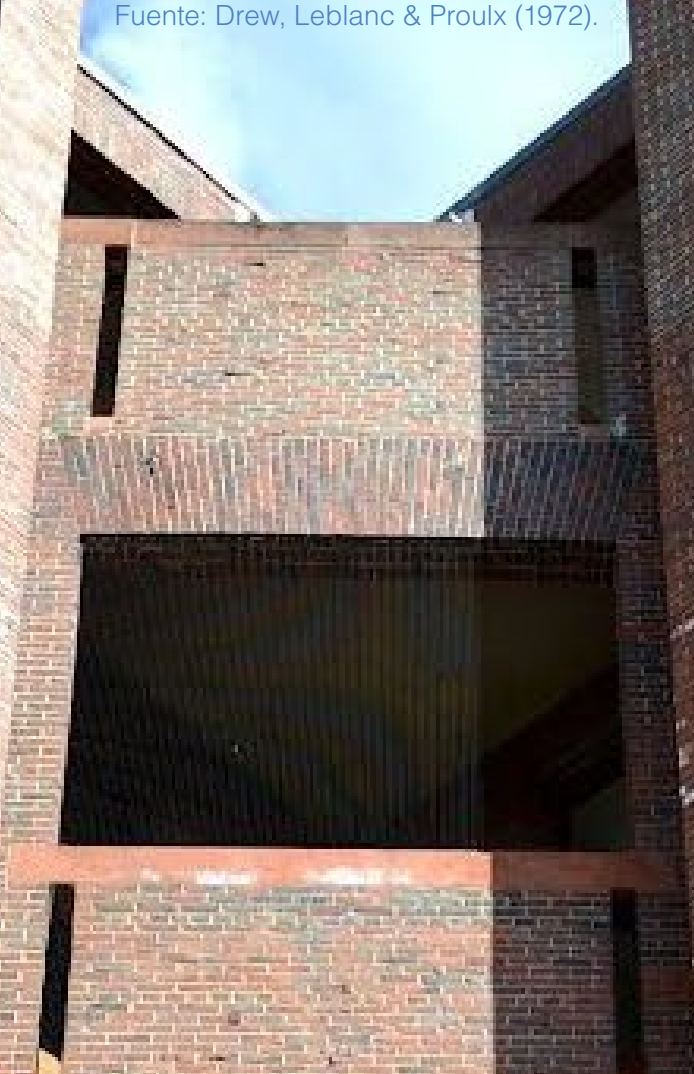

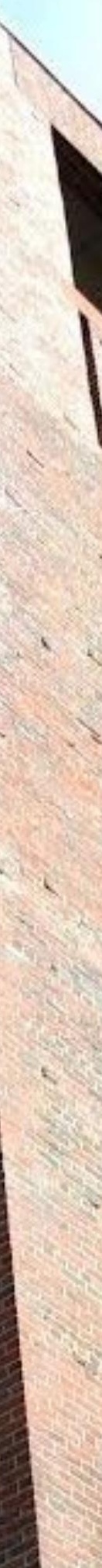

el cuerpo. Los identificadores espaciales explican la relación entre espacialidad y corporalidad, entendiendo al cuerpo ("conciencia corporizada") como la articulación y anclaje que concibe a aquellos como referencias, inferencias y diferencias generados por el acto de habitar el espacio, ya que es impensable habitarlo sin una "pertinencia intrinseca de los (Wabitantes al lugar que se encuentran (Waldenfels, 2004, p. 24).
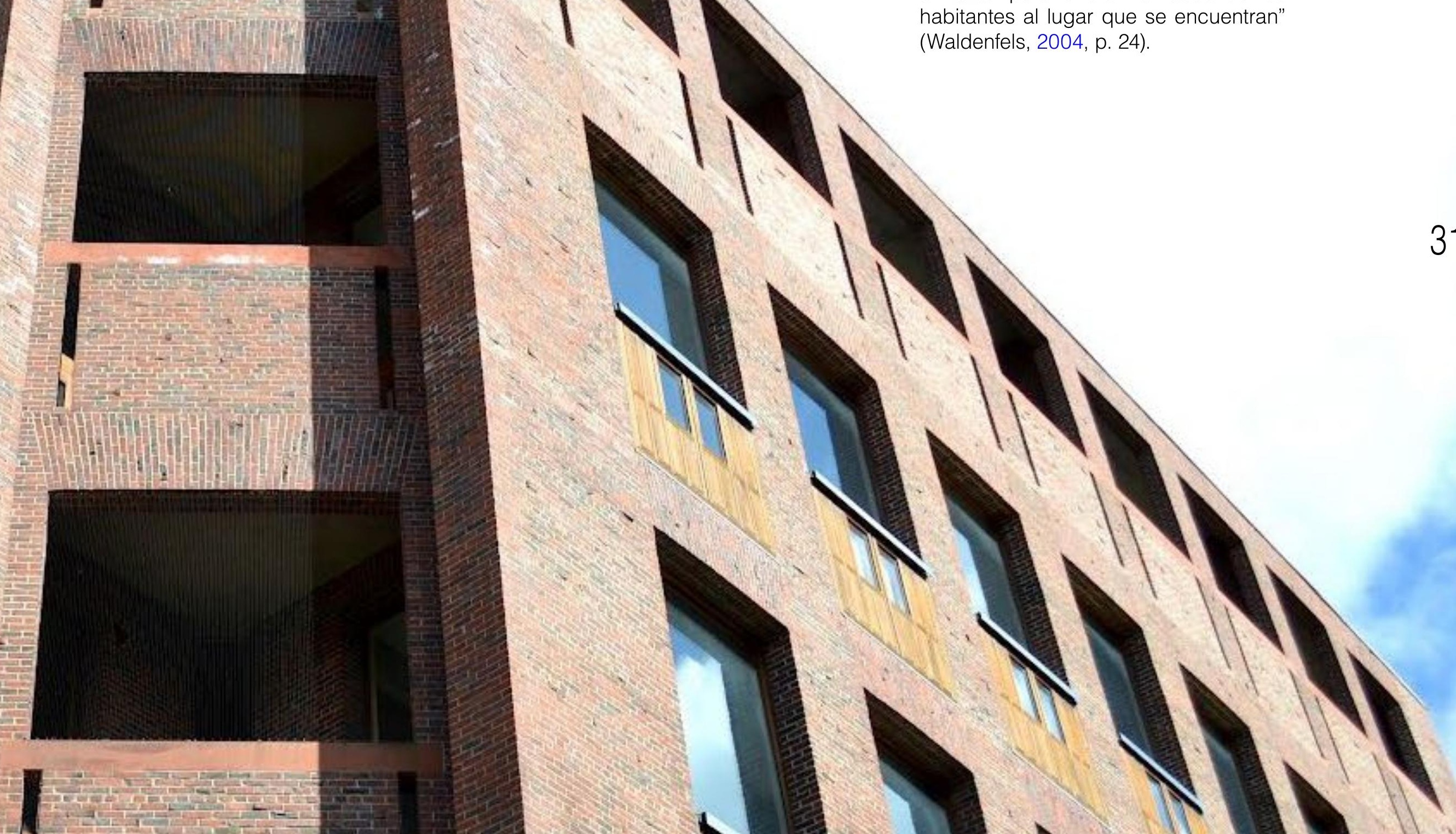
El dónde del estar en. Es el dónde de aquel que dice estoy aquí o que se pregunta por el aquí, es un sitio o lugar entre otros espacios, que va variando de acuerdo con la posición del que genera el aquí, constituyendo algo que puede ser solo mostrado. El aquí identifica el sitio o lugar en el que se encuentra en un determinado momento. Para construir el aquí debe determinarse el dónde que será inseparable del quién que ocupe el aquí. Este aquí constituye la primera relación de espacialidad y corporalidad. El aquí conforma la expresión lingüística de encontrarse en un sitio. Ese lugar que ocupa el cuerpo «conciencia corporizada» encontró el lugar genuino del aquí en dónde algo se muestra. Al tener un cuerpo el aquí, los algo toman sentido de representación en el espacio. El aquí como el ahora en el discurso son muy pocos absorbidos por el espacio y el tiempo respectivamente.

Especies de espacios. En cuanto a la matemática cartesiana, las orientaciones del lugar son identificadas a través de ejes medibles, como $x, y, z$, correspondiendo a derechaizquierda, delante-detrás y arriba-abajo, respectivamente, pero si estas orientaciones espaciales hacen referencia al espacio que es habitado corporal-mente, debe inferírseles el significado de "especies de espacio" (Perec, 2001), ya que constituyen un conjunto de referencias que pertenecen al espacio y lo especifican. El centro de referencia de estas espacies espaciales lo constituye el aquí corporal, que marca el principio ${ }^{3}$ del orden espacial con lo que implica y connota, "adquiriendo los rasgos de un no lugar que remite a la extrañeza" (Waldenfels, 2004, p. 25).

${ }^{3}$ Como origen, base, razón y fundamento

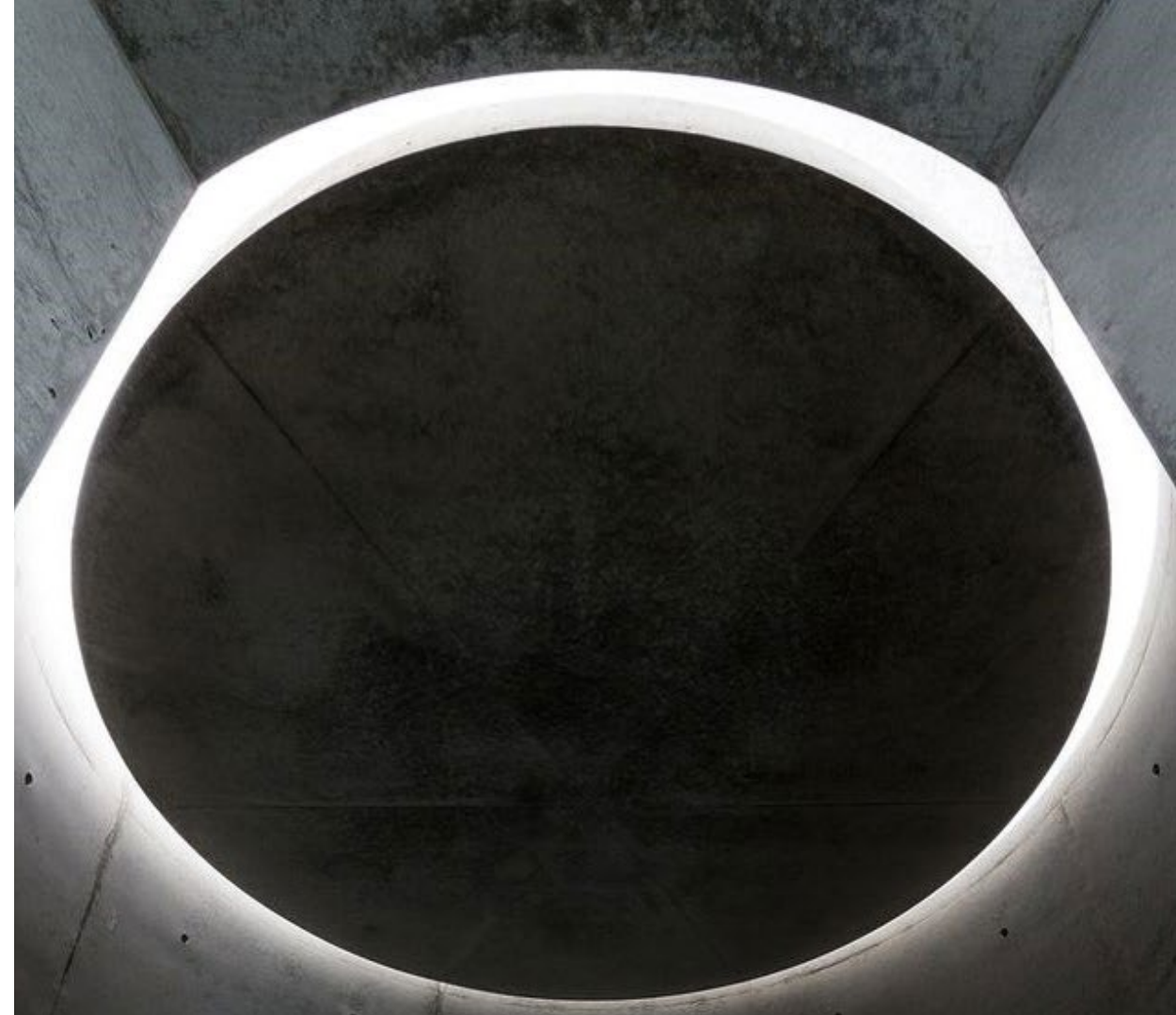

Fig. 3a. Esfera de hormigón dentro del Ando Museum.

Fuente: http://benesse-artsite.jp/en/art/ando-museum.html. 



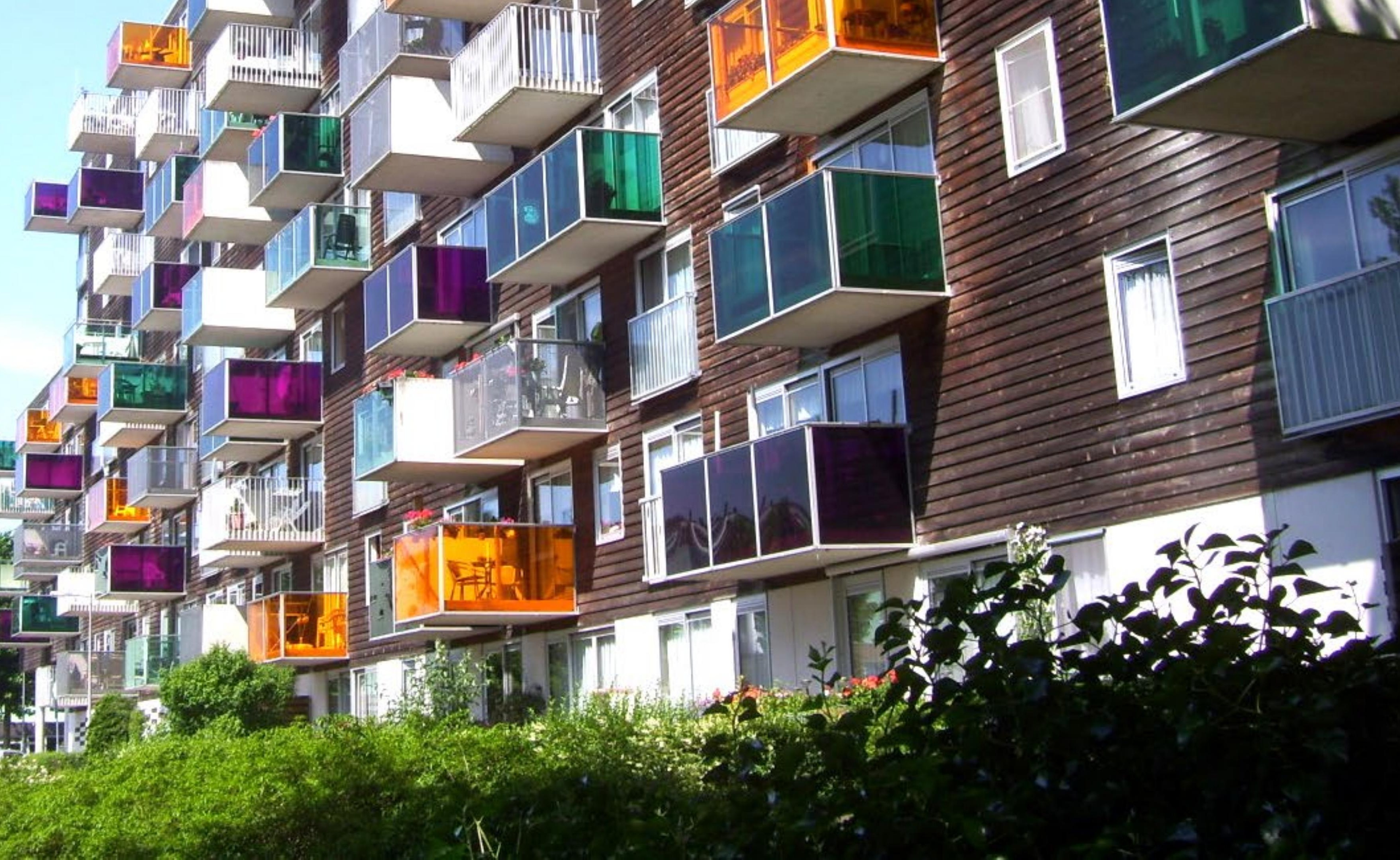




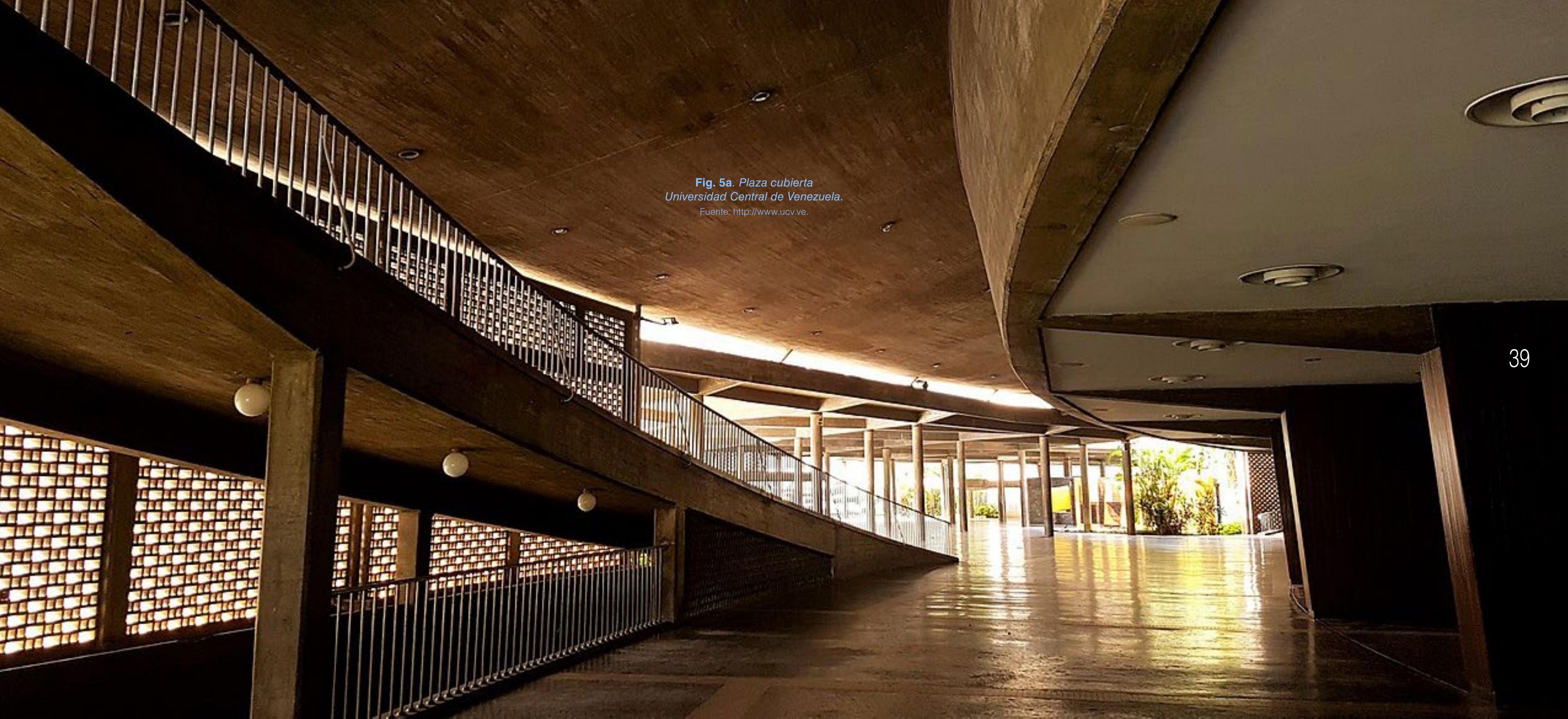


La derecha y la izquierda en los sentidos, como el ojo y el oído, no constituyen una gran diferencia, pero en cuanto a la orientación cerebral del cuerpo humano, existe una desigualdad que se afianza al sumar acciones, como escribir, el modo de ver el espacio pictórico, etc. Y, para acentuar aún más la diferencia, a esto se le suman las connotaciones de orden jurídico y moral, donde la derecha es lo legítimo, lo normal, lo adecuado, lo cónsono, lo regular; mientras que la izquierda es lo ilegítimo, lo torpe, lo desviado, lo rebelde, lo irregular. Aunque en algunos casos, a la izquierda se le saca provecho, como el caso de los zurdos en el deporte o en la agilidad para el pensamiento creativo.

Estas especies de espacio no son rigi40 dizadores del movimiento en el espacio, al contrario, se entienden más como referencias que pueden cambiar de acuerdo con la dirección hacia donde se dirija el sujeto que conforma el aquí, es decir, que las direcciones se relativizan de acuerdo con el movimiento. Esta relatividad, debida al movimiento, genera otras orientaciones, como volverse hacia, volverse desde, adelantarse y retroceder, ya que no es solo la orientación vertical la que se pone en movimiento hacia delante y detrás (Waldenfels, 2004).

Fig. 5b. Plaza cubierta

Universidad Central de Venezuela.

Fuente: Alfaro (2014) - Own work.

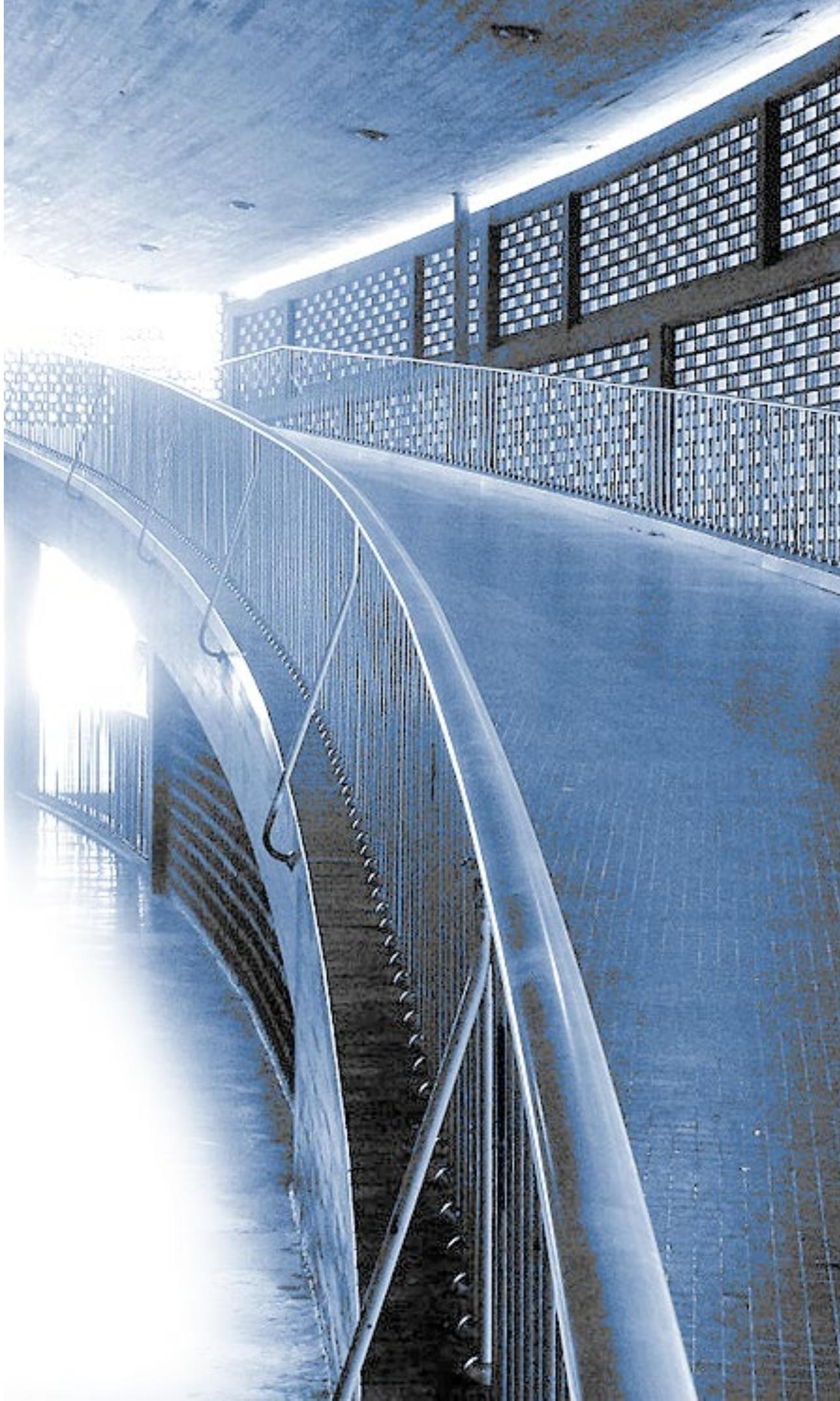


Fig. 6a. International Center for Sports

Innovation In The Natural Environment

"The Ring" Caceres, Spain.

Fuente: http://www.jmsg.es/filter/completed/THE-RING

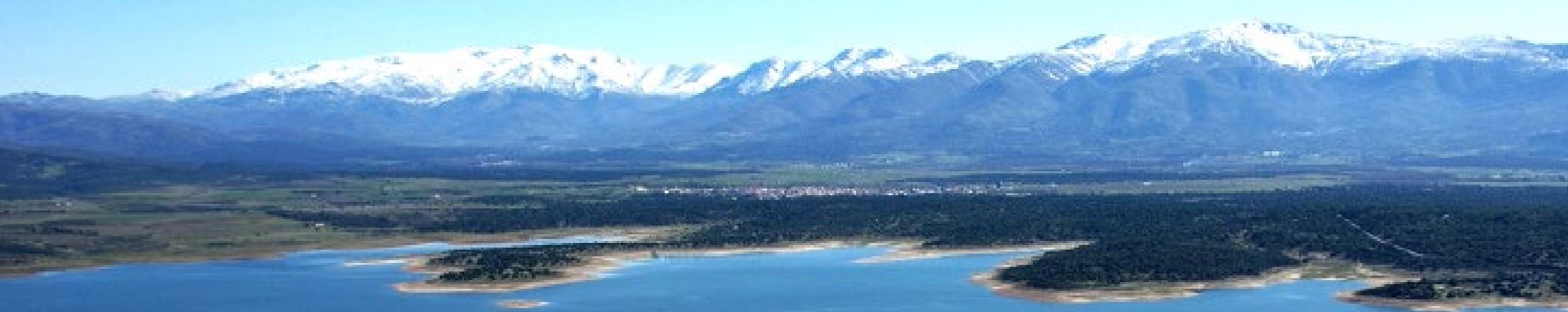

es un proceso abierto que, mediante divergencias, es arrojado constantemente fuera del camino. No se trata de movernos en el espacio sino de que este movimiento construya espacio, y si construir, según Heidegger (1994), es habitar, entonces el hecho de movernos es un componente ${ }^{4}$ de habitar corporal-mente el espacio. Es quizás el elemento fundamental, ya que es el movimiento el que permite esa dualidad del espacio, el que permite ser y estar en dos espacios distintos al mismo momento; ese movimiento en que el cuerpo no va con la mente, sino que cada uno es independiente y atiende a espacios y momentos distintos. Es el rompimiento del componente esencial del cuerpo en que de ser un ente es corpo-mente y habita corporal-mente.

${ }^{4}$ Se escribe com-ponente, con guion, para hacer énfasis en la idea de conformar y ocupar una posición.

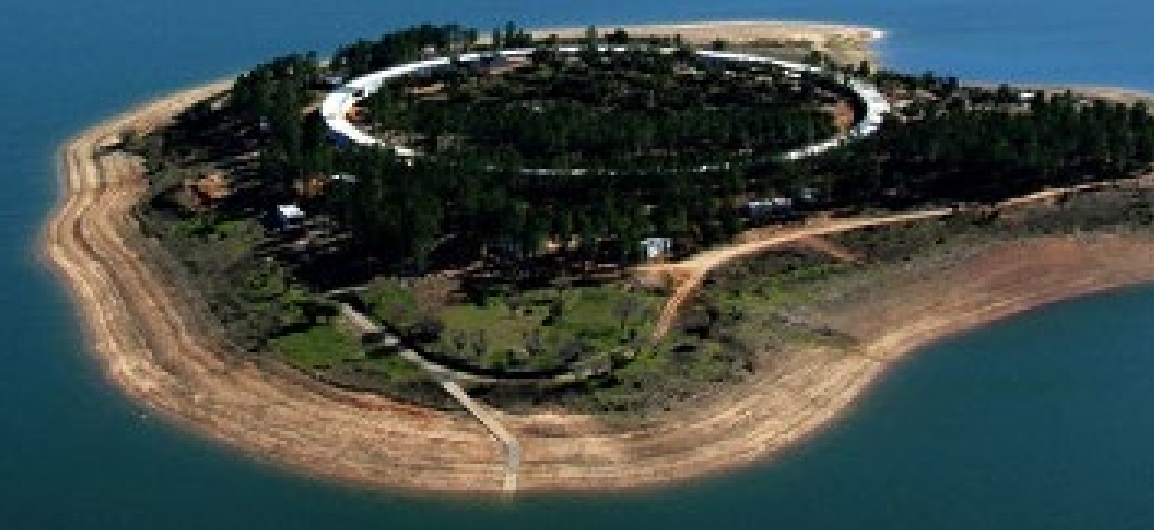


Cuando la proximidad no es cuestión de espacio. Un componente más para la construcción del espacio lo constituye la dicotomía de la proximidad y la lejanía, que no establecen un asunto solo de distancia, sino de los medios y las técnicas de locomoción. De acuerdo con éstos, la relación que se establece dependerá entonces de la velocidad de locomocion, y cuando el espacio es cruzado por el cuerpo se anclara a esto dependiendo de lo que perciba a través de ese cruzamiento. Según Viritio (Waldenfels, 2004), de acuerdo con las velocidades, a lo cual se le añade el tiempo al componente espacial, existen tres el movimiento corpóreo; la mecánica que depende de los medios de transporte; y la electrónica, que se realiza a la velocidad de la luz y que puede convertirse en proximidad absoluta. ¿Será entonces qué ahora la proximidad se mide en tiempo?

El limen del lugar corporal: dentro y fuera. Si el aquil es solo orientación y punto de partida del movimiento, entonces ese aquí constituye un cualquier parte, es decir, un espacio infinitamente abierto, como si fuese en ninguna parte. Tal infinitud se rompe cuando el aquil genera un lugar propio, y lo que toma sitio se encierra asimismo en ese lugar, convirtiendo el aqui en lugar de estancia, un lugar que es rencialidad se origina en el limite que distingue un hacia dentroy un hacia fuera construyendo lugares con valores distintos: dentro, fuera zona interior, zona exterior. Donde el dentro está marcado, es un integrante más de la diferencia; es el lugar donde se separan los límites, es donde alguien o algo se separa.

Fig. 6b. International Center for Sports Innovation in The Natural Environment
"The Ring" Caceres, Spain.

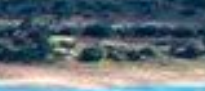

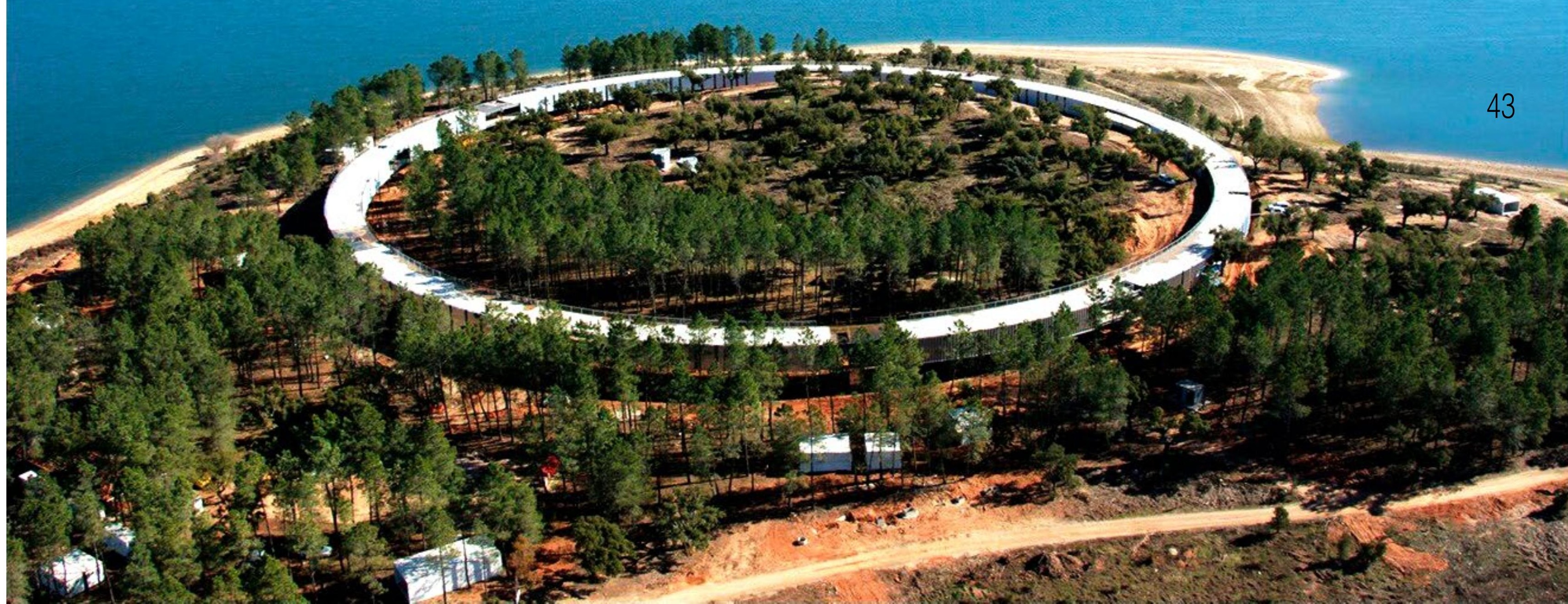


La diferencia entre el dentro y el afuera está enmarcada en el espacio como contenedor con contenido y en la determinación de la espacialidad como exterioridad (Waldenfels, 2004). El adentro solo tiene sentido para quien se encuentra aquí. El dentro y fuera le otorgan un carácter tópico a lo propio y extraño que exigen en este instante un "topografía de lo extraño" (Waldenfels, 2004, p. 28). El hacia dentro comienza en el propio cuerpo y la piel es la superficie límite que hace contacto con el afuera, extendiéndose la esfera corporal con los artefactos y la vivienda y todo lo que el hombre inscribe en su experiencia. Algunos elementos que conforman el espacio arquitectónico proponen una diferenciación entre el adentro y el afuera y pueden ser alterados en su permeabilidad, estabilidad y/o movilidad, dependiendo de la identidad del lugar y el grado de delimitación entre ese adentro y afuera. Es así como el cuerpo define el limen del lugar no sólo como un dentro y fuera, sino también, como esa condición de un aquí y un allá.

Fig. 6c. International Center for Sports Innovation In The Natural Environment "The Ring" Caceres, Spain.

Fuente: http://www.jmsg.es/filter/completed/THE-RING.

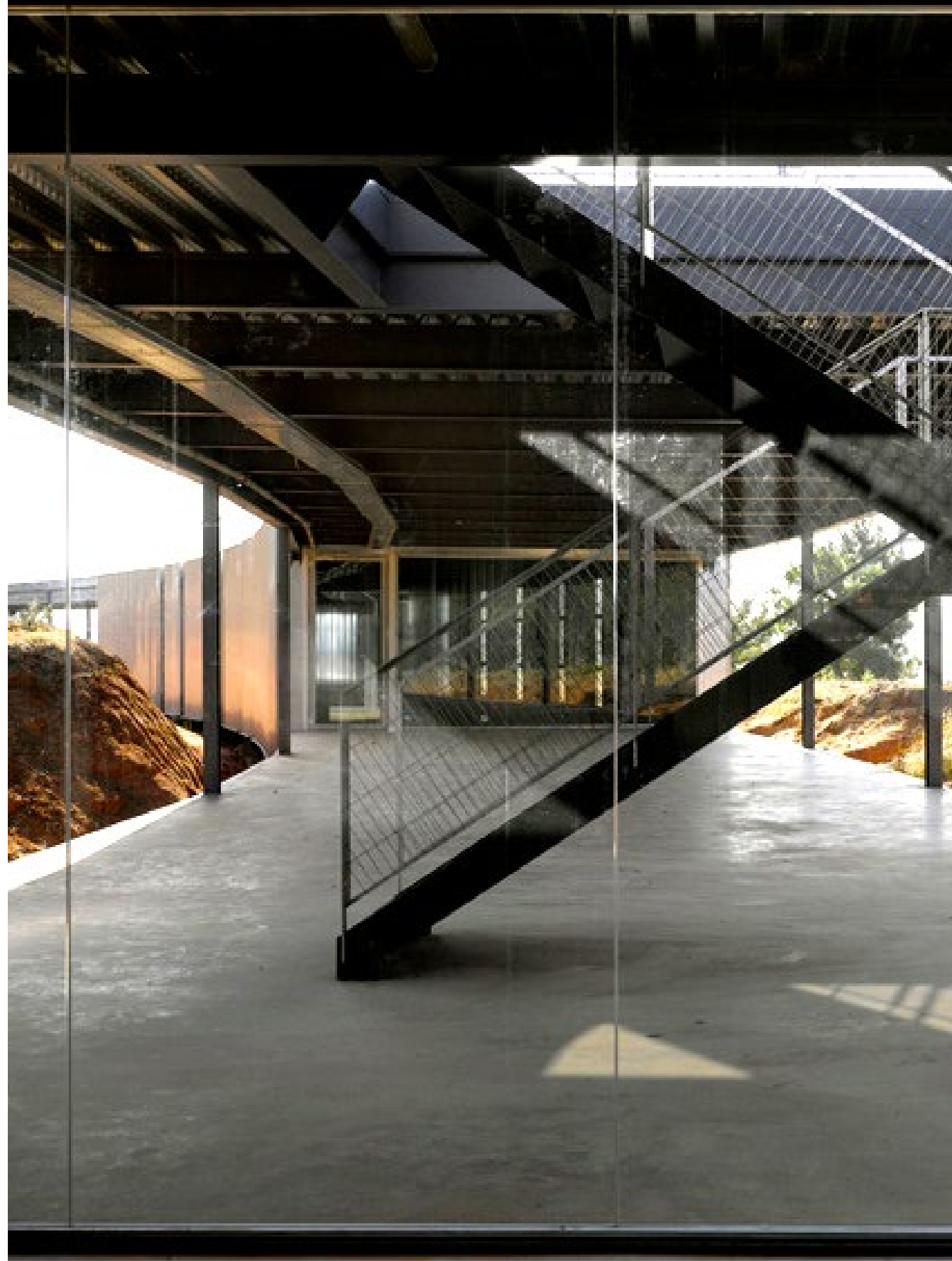




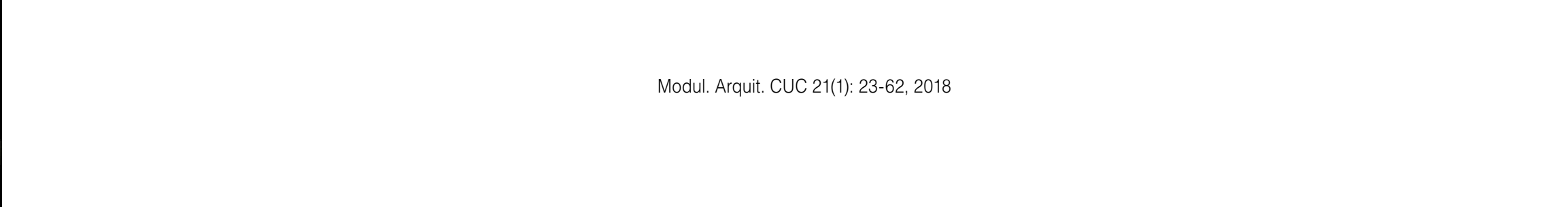

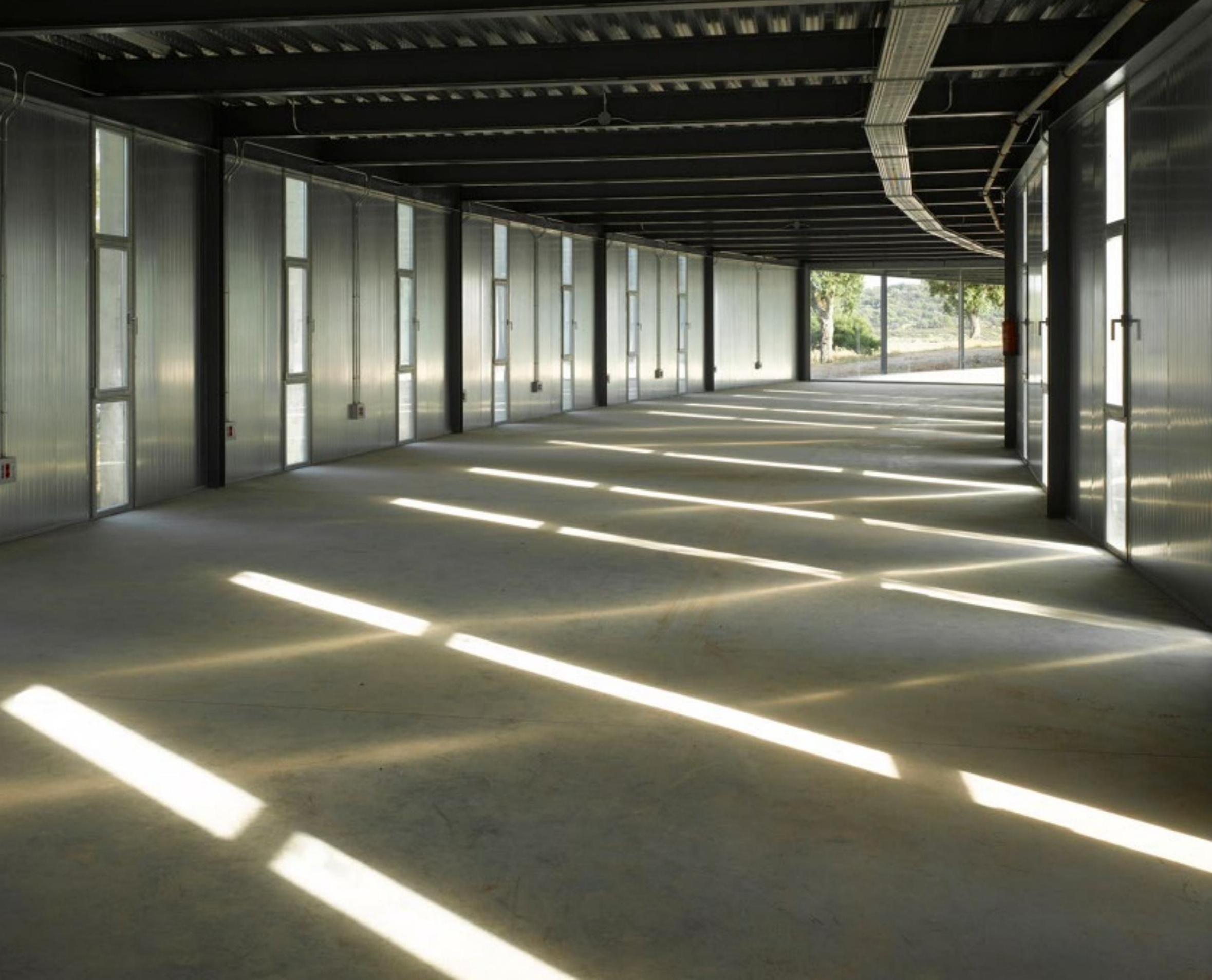


$\sec 2 \mathrm{crapa}$

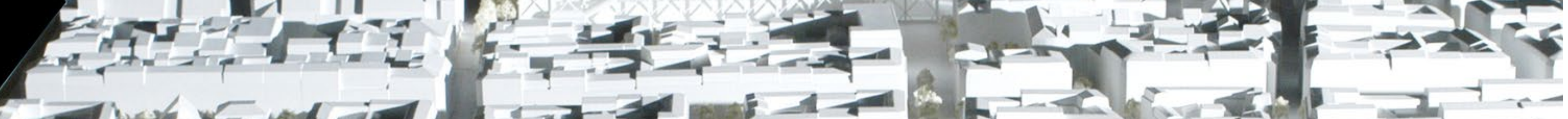

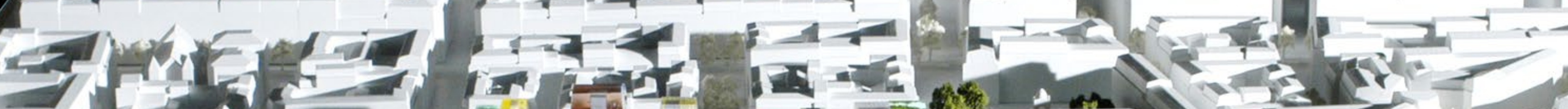

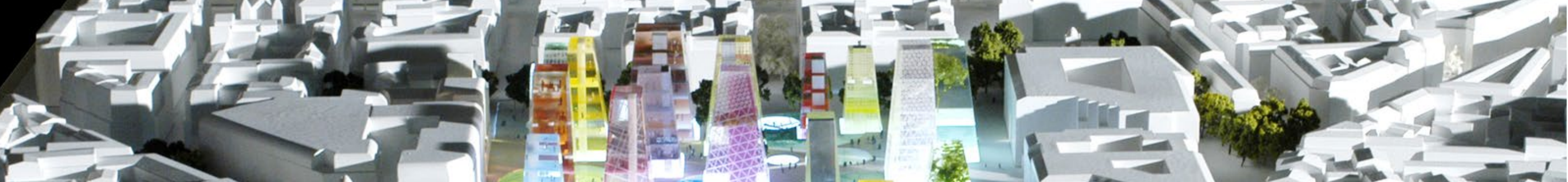

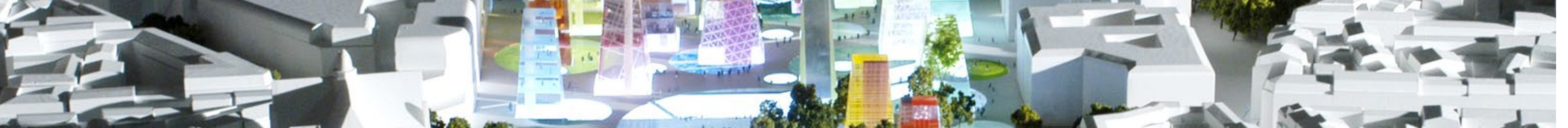

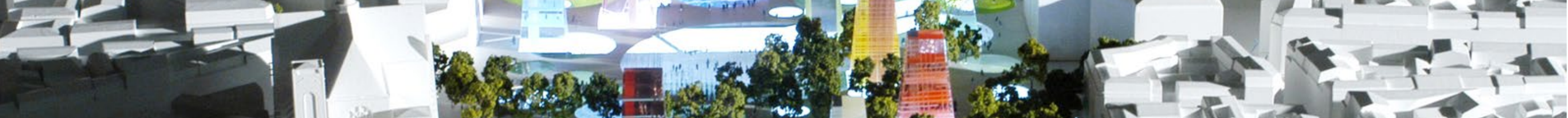

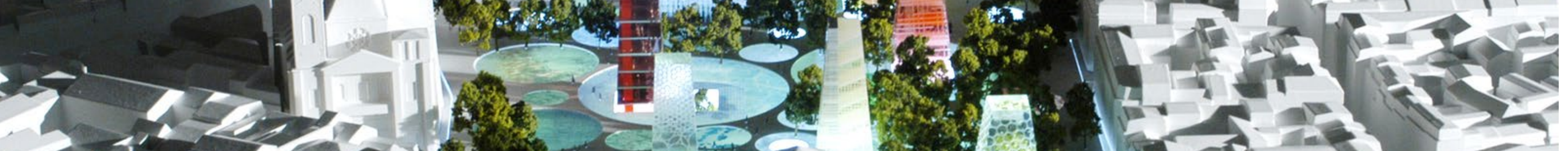
P $-19-14=$
Cualidades del continente espacio. Este identificador de espacio se determina mediante el modo y la manera como alguien o algo ocupa el espacio y se relaciona oscilando entre grados de contención del espacio. Los espacios pueden estar congestionados, descongestionados, pueden ser amplios o estrechos, dispersos o concentrados, aglutinados o desaglutinados. Estar lleno y vacio no se mide por metros cuadrados, sino por grados de contacto social o de tránsito, es decir, el grado de contacto social es lo que determina si el espacio es lleno o vacio. Esto define, por recio que se ocupa y que hace lugar la conciencia del cuerpo

Relaciones espaciales. El lleno y el vacío estan intimamente ligados a la disposición y distribución del espacio y de las cosas en el espacio. Disponer y distribuir se refieren a cómo se relacionan las cosas en un contexto. Si se transfieren estos conceptos de articulación espacial hacia la ciudad se pone en evidencia la heterogeneidad, tanto en la disposición y distribución como en la identificación de los lugares. Esta heterogeneidad puede generar lo que Foucault 
El cuerpo entre el topos

\section{y la heterotopía}

El cuerpo situado entre el topos y la heterotopía indica que no está completamente en el mismo lugar, que se encuentra creando y/o re-generando heterotopías. El espacio re-integrado no es homogéneo o constituido por una sola cosa, de una sola forma o de un solo modo. Entre espacio y espacio se producen oposiciones, desplazamientos, desmembramientos, rupturas, hendiduras, agrietamientos, de manera "que nada ni nadie está nunca completamente en su lugar" (Foucault, 1968). Lo anterior, tal cual como se expone, muestra que habitar corporal-mente el espacio construye heterotopías, mediante el aquí y en otra parte; los lugares comunes y los extraños; la telepresencia; la actualidad, habitualidad y virtualidad del movimiento corporal; los lugares conmemorativos y la hospitalidad.

Fig. 7b. Les Halles "Project" París, Francia.

Fuente: http://oma.eu/projects/les-halles

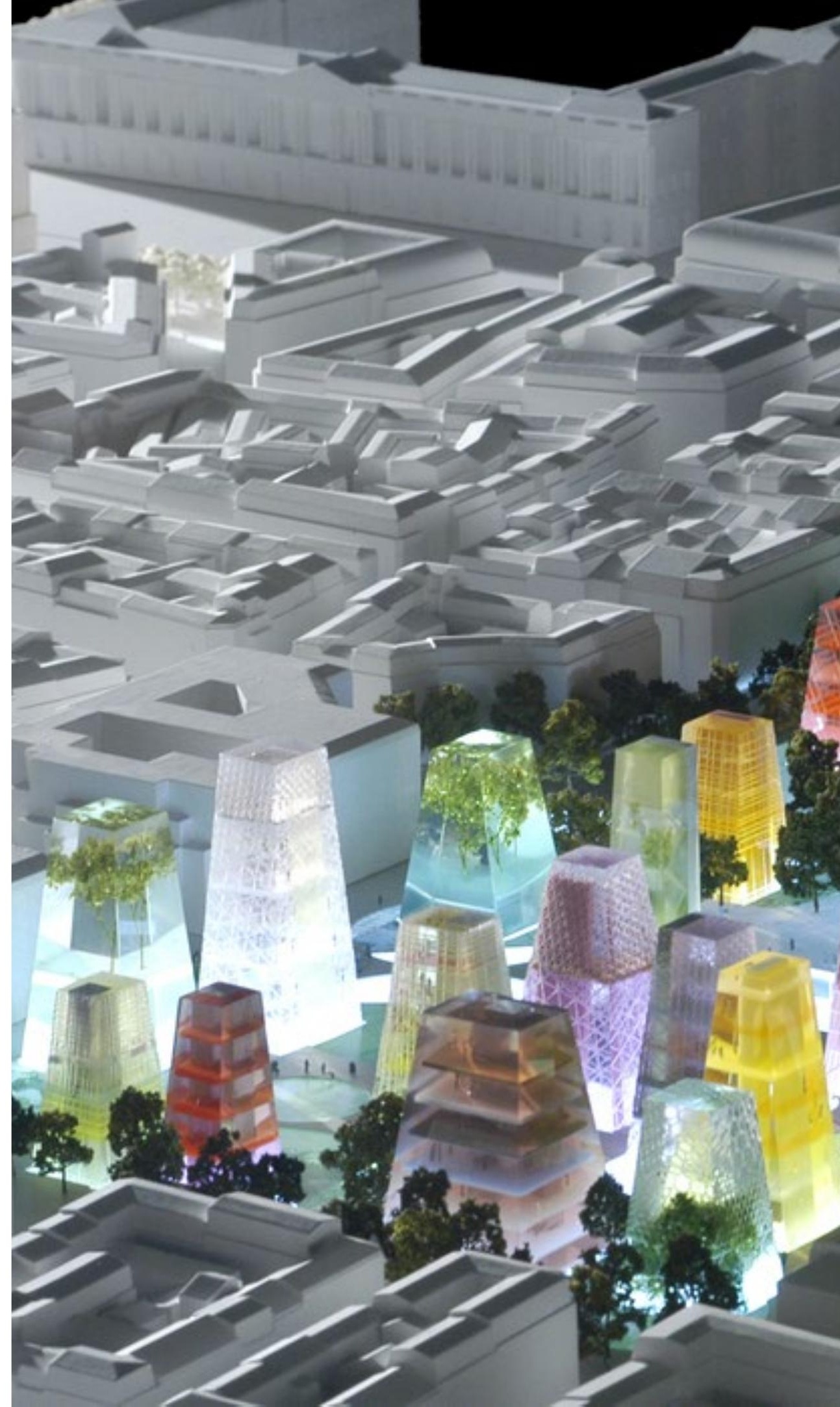



HABITAR CORPORAL-MENTE EL ESPACIO COMO CONSTRUCCIÓN DE HETEROTOPIAS

La virtualidad como continuidad entre el aquí y el allá. La existencia espacial tomando en cuenta el movimiento corporal obtiene una densidad temporal, ya que el lugar futuro es un por-venir ${ }^{5}$ de posibilidades y el lugar pasado construyó un aquí.

El aquí actual del cuerpo actual, se densifica en el aquí habitual del cuerpo habitual" (Foucault, 1968), porque posee con continuación. La orientación corporal y los movimientos corporales están anclados a la actuación del cuerpo, ya que este ha adquirido la costumbre de sus modos por repetición o tradición para constituir la orientación y el movimiento, además del conocimiento perenne de los miembros de su cuerpo. La orientación al encontrarse desconcertado en un espacio es ayudada por el hecho de tener guardado perennemente en la memoria el control de los miembros del cuerpo y gracias al redescubrimiento del lugar resucita el "sí mismo localmente asentado" (Foucault, 1968).

${ }^{5}$ Entiéndase como porvenir y como lo que está por venir.

Fig. 8b. Water-Purifying 'COSMO'.

Fuente: Miguel de Guzman

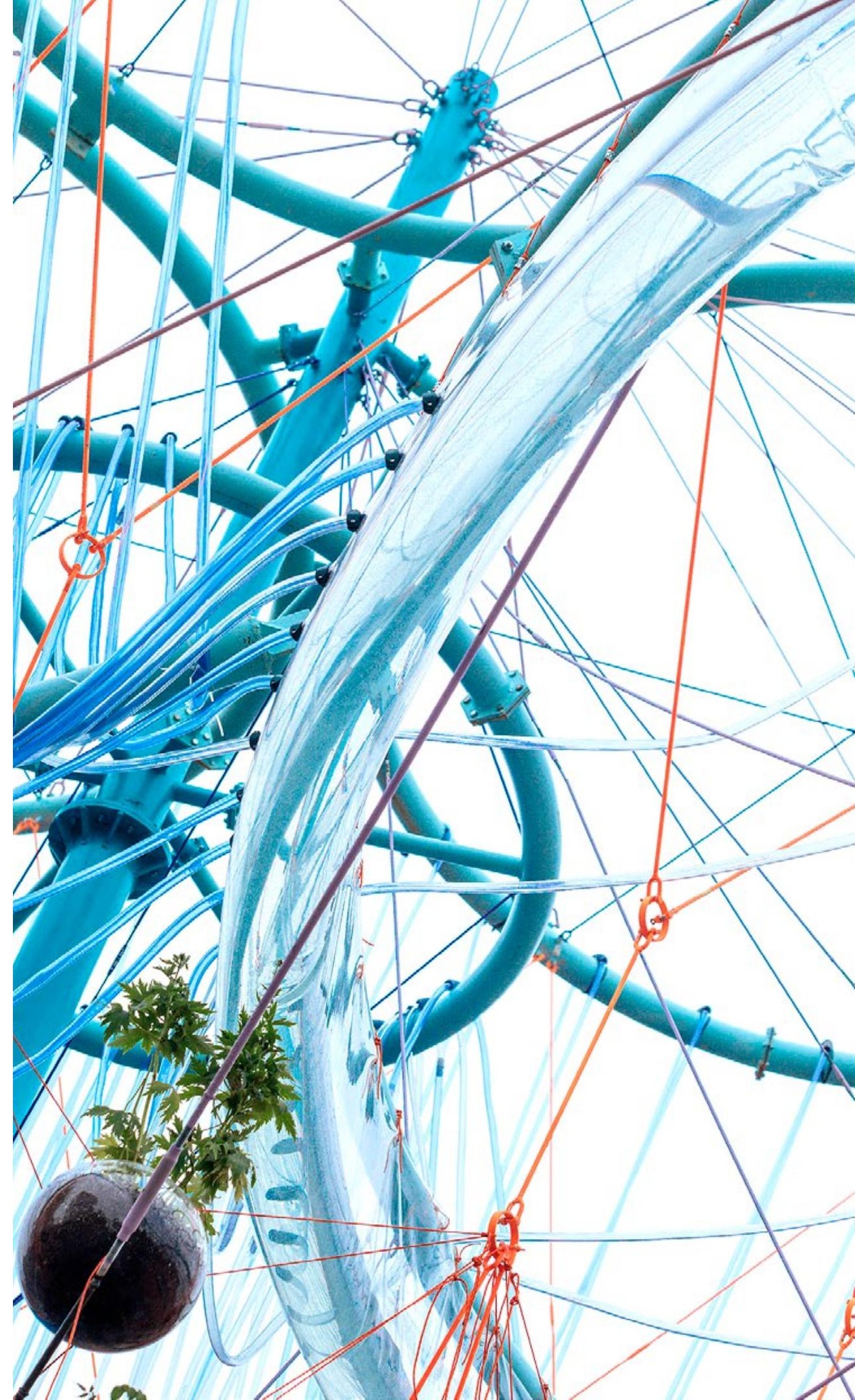




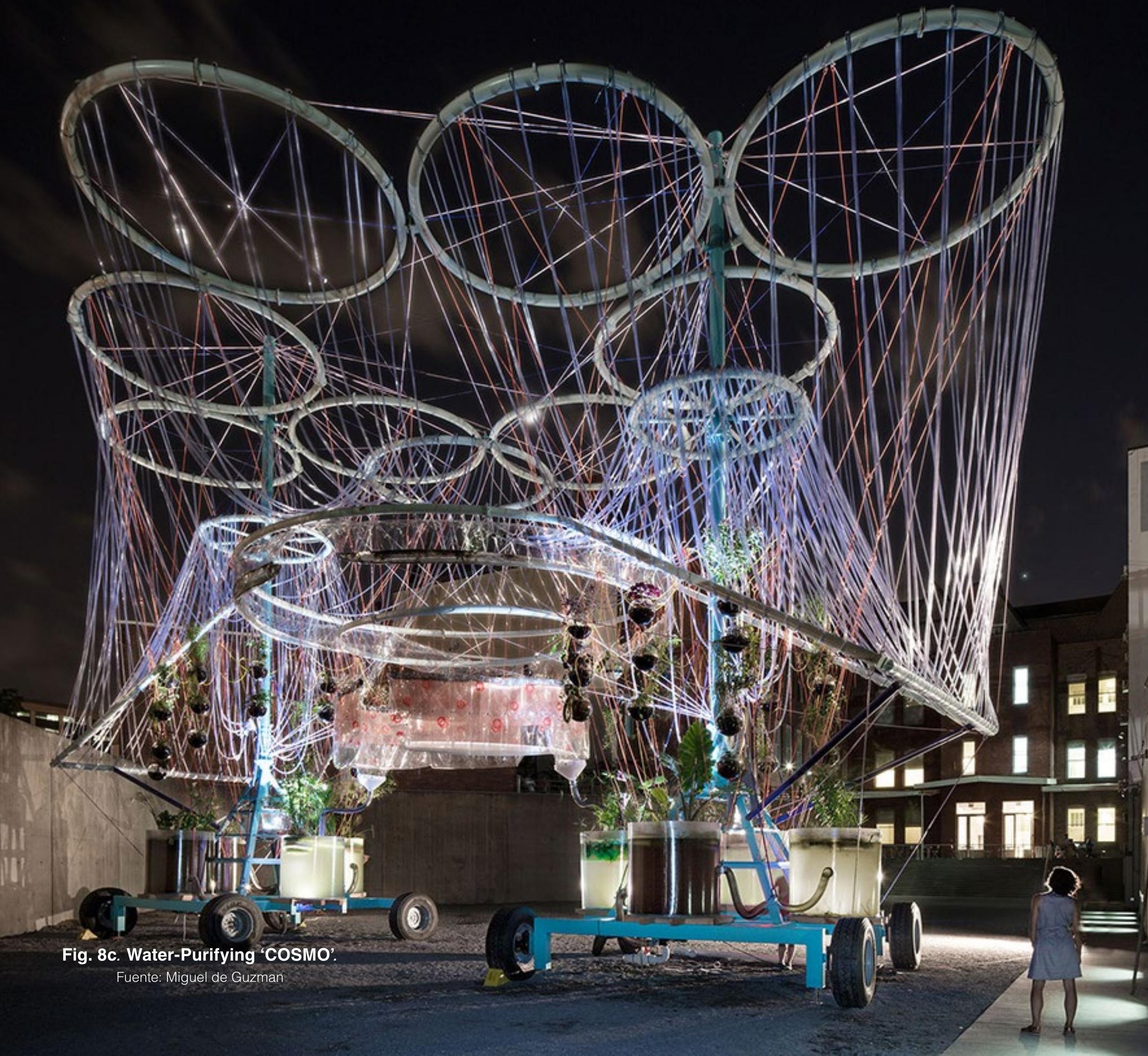




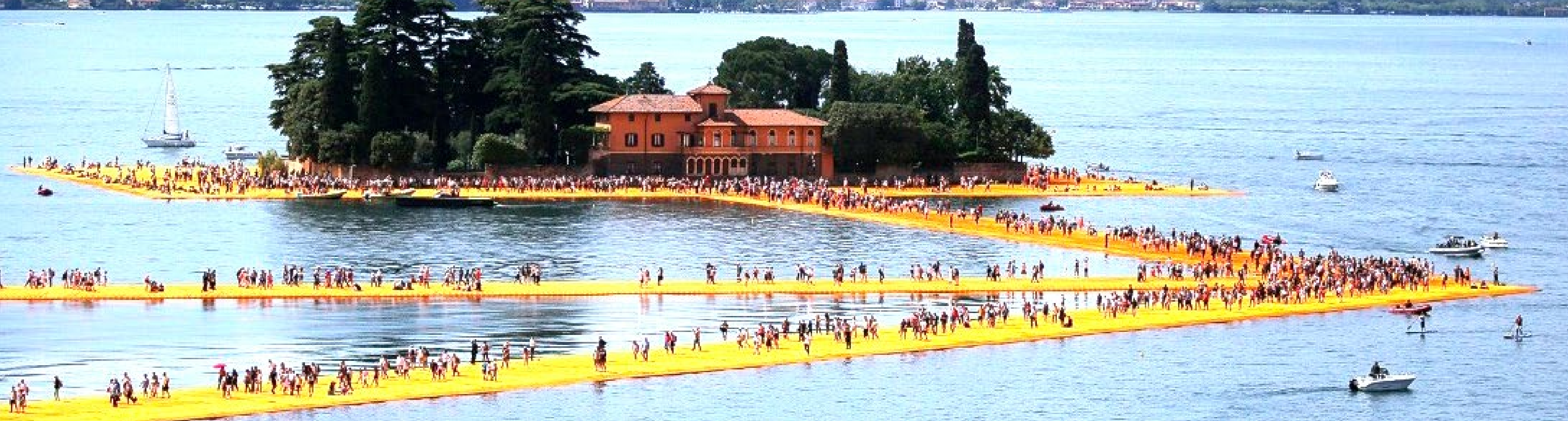


Al mismo tiempo que el cuerpo se ubica en un aquí corporal, se abren las posibilidades de un "allá" ${ }^{\circ}$ de un cuerpo virtual que está siempre en otra parte, hacia dónde sus inquietudes lo conducen cargado con sus cualidades. Nomadismo y sedentarismo oscilan entre las posibilidades extremas de un deambular y un asentarse. Ambas son posibilidades que pertenecen a la realidad, pero explican claramente la polaridad general entre el lugar que ocupa el cuerpo en la realidad y el lugar que ocupa el alma en su andar.

El sentido de posibilidad y realidad no se contradicen, pero sí pueden enfrentarse, ya que si el sentido de realidad incrementa, reduce las posibilidades. La posibilidad y la realidad se encuentran inversamente proporcionadas. Si la primera aumenta, nos vamos a una virtualidad en donde se pierde toda sujeción a la realidad; y si la segunda aumenta, incursionaremos en una realidad que pierde posibilidades. Es decir, los extremos constituyen casos clínicos, como la ruptura entre la actividad motriz y el saber intelectual.

El avance tecnológico y la era de la información conducen a atribuirle más peso al sentido de posibilidades que al de realidad. Si bien la tecnología multiplica las opciones de darle sentido a la realidad y a las posibilidades, también conduce a cuestionarnos sobre la realidad de las acciones, del movimiento corporal, las descontextualizaciones y a las acciones inmersas en ellas.

${ }^{6}$ Quiere decir que se encuentra en el espacio de posibilidades y no en el espacio real.
El presente real y el presente posible, combinados en la actualidad, las costumbres que nos asientan en el lugar, inmersas en la habitualidad y las posibilidades abiertas del movimiento corporal, expresadas por la virtualidad, nos enrumban hacia la construcción continua o discontinua de heterotopías.

Espacio-tiempo como lugar de la memoria. El redescubrimiento del lugar y el control de los miembros del cuerpo contradicen la tradicional correspondencia entre tiempo como interior y espacio como exterior.

El cuerpo es instrumento, marca y apunte originario. Las marcas dejadas por la experiencia son indicadores de lo que éste realiza. La costumbre es producto del modo habitual o proceder establecido "por tradición o repetición de lo que hacemos" (DRAE, 2007), es un "co-actuar con el cuerpo" (Waldenfels, 2004, p. 27), induciéndole aquella acción al tiempo a través de mover corporal-mente el espacio.

Algunos contenidos de espacios o cosas generan centros de energía que trascienden su uso, marcando ese momento donde el acontecimiento que conjuga espacio-tiempo-posibilidad-realidad le otorga contenido, transformando ese espacio-tiempo en lugar de la memoria, que permanecerá en el recuerdo dependiendo de cómo sea cultivado, ya que al actuar un olvido inducido o no, todas las cosas pueden convertirse en sustituibles dejando sin rastro y sin fundamento la memoria. 
Los lugares y monumentos guardan la singularidad que sella un acontecimiento insustituible, mientras que los lugares que no son buscados pierden el sentido de particularidad, es decir, no tiene sentido un lugar sin quien lo busque.

Proxemia virtual. En las sociedades humanas organizadas tradicionalmente, la proximidad y la lejanía se gradúan de acuerdo con el dominio total del lugar, circunscribiendo estos dominios a sus "círculos de vida, concéntricamente ordenados, que se extiende desde el familiar mundo cercano hasta un mundo lejano, subordinado a aquel" (Waldenfels, 2004, p. 32), haciendo evidente una jerarquía de relaciones. Este sistema de relaciones entra en crisis cuando la realidad se fragmenta y se multiplican los egocentros, aumentando las posibilidades de conquistar el espacio, ya que el dominio del mundo incluye también el domino del espacio (Waldenfels, 2004).

Fig. 9b. Floating art lets.

Fuente: Grassani for The New York Times

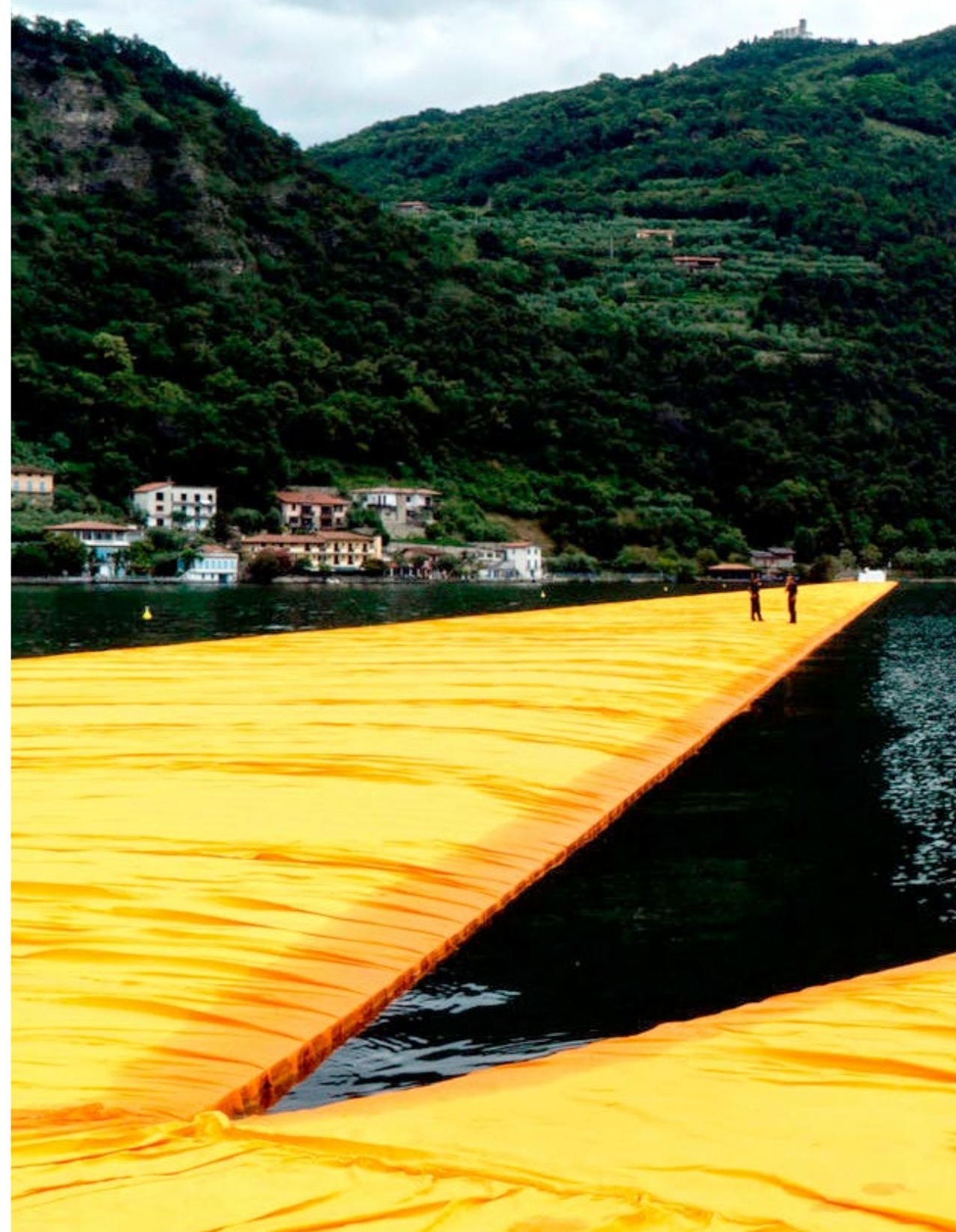


Fig. 9c. Floating art lets.

Fuente: Grassani for The New York Times

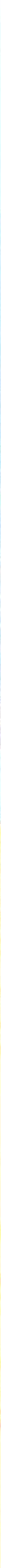




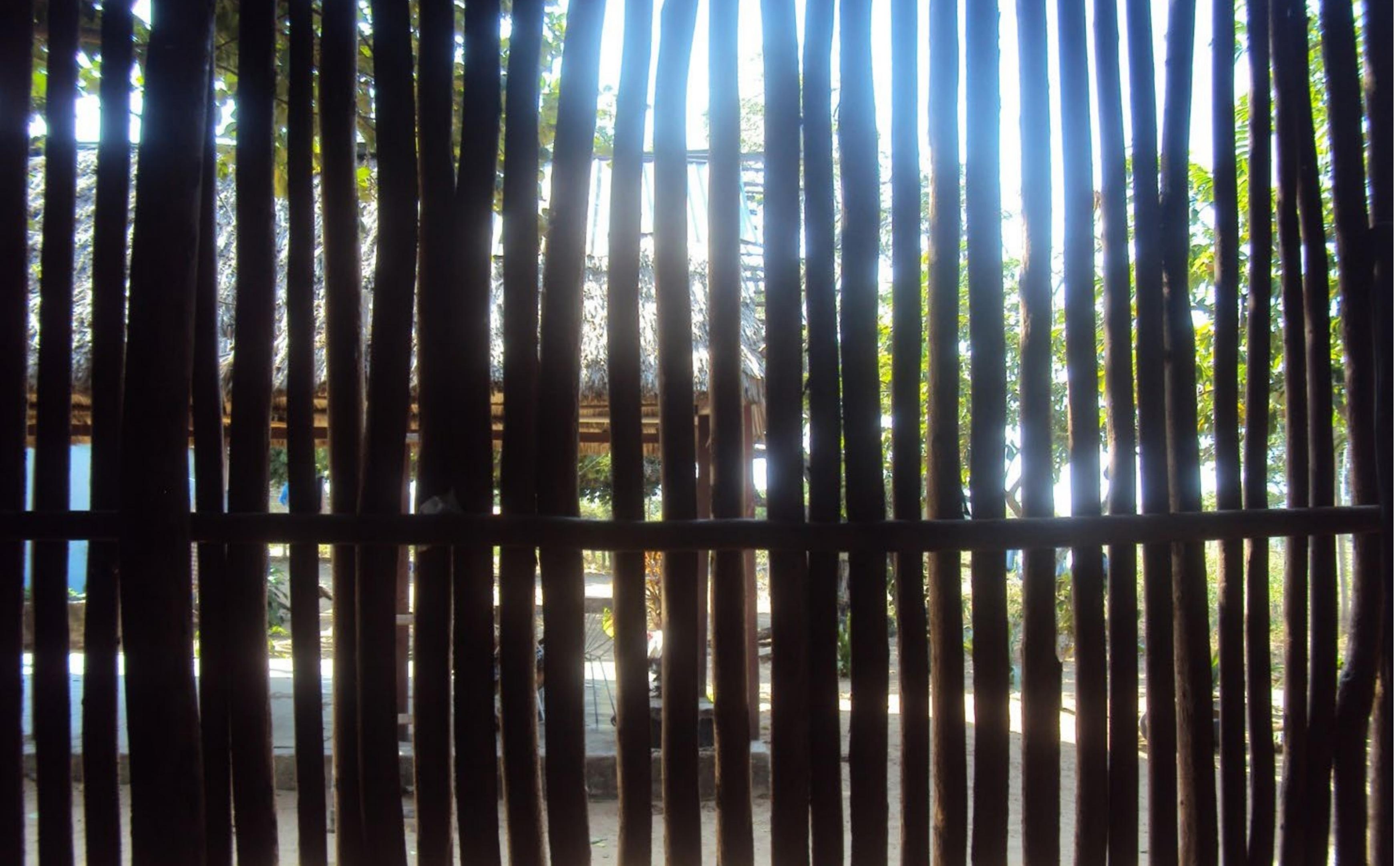

La proximidad electrónica trae en tiempo real el acontecimiento más entre aquí y allí, permitiendo un mayor dominio de los espacios que acerca la telepresencia a la omnipresencia de Dios.

En la telepresencia se incluyen las posibilidades de teleacción, que a través de los telemedios pueden transformar un hecho o espacio local cotidiano en un hecho o espacio mundial. Podemos estar aqui y en cualquier parte, convital como lo expone Viritio (Waldenfels, 2004).

La lejanía no tiene que ver solamente con la distancia, sino también con la extrañeza, de la visión extraña y puedo estar" (Waldenfels, 2004 p. 33) se muestra como una "imposibilidad vivida", pero la aproximación pudiera trascender y hacer visible lo invisible. Si lo extraño estuviese próximo, no significaria lo que significa, pero en la telepresencia fracasa el más alla de..., transformando de esta manera el espacio que se genera en un no lugar, ya que no se llega a habitar en todas sus dimensiones. 
Lo común y lo extraño al cuerpo. Lo extraño define los límites del espacio. No son límites en el sentido de elementos geográficos o marcas traspasables, sino aquellos que delimitan un adentro y un afuera, como se explicara en el segundo apartado. Los límites entre lo propio y extraño aseguran, permiten e impiden. Los límites espaciales se muestran en forma más o menos simbólica y a medida que son experimentados, entendidos, reconocidos, llevan consigo un significado simbólico, como una "representación sensorialmente perceptible de una realidad, en virtud de rasgos que se asocian con ésta" (DRAE, 2007). La experiencia con el cuerpo y/o a través de él lleva a descubrir su espacio, sus posibilidades, su actualidad y su vulnerabilidad.

El límite, al mismo tiempo que separa, une dependiendo del sentido que le demos y del punto de vista en que lo miremos. Cruzar el espacio transforma sus posiciones, localizaciones y percepciones. La contraposición entre cualidades espaciales y significados simbólicos le restan valor al símbolo, ya que, por ejemplo, entrar y salir en un espacio no representa que ese espacio esté constituido por dos mitades contrarias.

Un lugar es extraño "cuando me es inaccesible o no pertenezco a él" (Waldenfels, 2004, p. 34), esto le confiere un carácter de exclusividad. Lo propio crea alrededor de sí un campo propio que tiene como contrario una extrañeza del mismo tipo; el limite de este campo o zona depende de los atributos que le otorguemos al límite. Dos variantes intervienen en la relativización de los límites del lugar propio: la primera indica que estos límites pueden formar parte de un lugar total en el que todo tiene coherencia, correspondencia y continuidad; constituido por lugares próximos o conocidos como si se encontraran en casa (Waldenfels, 2004). Y la segunda variante asume el ámbito propio como un orden legal con lo cual se conformará un ámbito de validez ilimitado, neutralizando los límites, ya que todos pueden ser admitidos, es decir, se anula el afuera, todo está incluido, no existe la exclusión.

Internet es una forma mixta (Waldenfels, 2004). No es el lugar común, no puede habitarse, no puede encontrarse un sitio propio, un sitio puede ser ocupado por uno y muchos a la vez, su recorrido es inmediato, negando la posibilidad que nos ofrece la acción de transitar. Solo hay diferencias y no extrañezas. Es un medio selectivo. Las extrañezas aparecen en los huecos y márgenes cuando no se tiene acceso o cuando se cae fuera de ella. Los límites en la red tienen que ver con la capacidad y la competencia frente a ese medio.

En la globalización contribuyen todas las culturas particulares, que, en teoría, dotan a todos los seres humanos con los mismos derechos. La globalización puede convertirse en un mercado mundial donde todo puede ser intercambiable, excepto el mercado mismo. En lo global se difuminan las diferencias entre lugar propio y lugar extraño, entre aquí y allí, y entre propiedad y extrañeza. El modelo de globalización es acorde con un "lugar común sin extrañezas, un espacio interior sin un afuera" (Waldenfels, 2004, p. 29), que anula las extrañezas; pero volver a un modelo como el modelo cosmológico, conduciría a desconocernos y desconocer lo que se nos revela y pronuncia. 


\section{1}

Fig. 10. Telar

Fuente: elaboración propia. 
En antinomia a la hospitalidad. La realidad nos recuerda la idea de hospitalidad como un carácter de la extrañeza que incluye un carácter del espacio. El espacio que habitamos es el lugar de contacto con los extraños donde los rechazamos, admitimos o los alejamos; el lugar de irrupción violenta que convierte lo propio en extraño, transformando la buena acogida y recibimiento en enemistad, convirtiendo el espacio propio en una fortaleza (Waldenfels, 2004). La extrañeza puede devenir de lo más propio haciéndonos sentir extraños en el lugar que podemos sentir más propio. Provocando así que concepciones opuestas se correspondan. Todo esto implica que nadie siempre está por completo en su sitio.

\section{Conclusiones}

El tránsito de la conciencia corporizada (Merleau-Ponty, 2000) en el espacio, las polaridades del espacio, las o-posiciones ${ }^{7}$, las articulaciones y las densidades conforman los referentes que marcan la acción de habitar corporal-mente el espacio, mientras que en el aquí y en otra parte, en los lugares comunes y extraños, en la telepresencia, en la actualidad, habitualidad y virtualidad del movimiento corporal, en los lugares conmemorativos y en la hospitalidad confirman el modo de habitar el espacio corporal-mente, la creación de espacios entre y la construcción las heterotopías.

\footnotetext{
${ }^{7}$ O-posiciones, por opuestos y por las posiciones que ocupan esas oposiciones
}

La presencia corporal no define la especialidad de ese cuerpo-mente que estén simultáneamente en un aquí y un allí. Habitar corporal-mente el espacio implica relaciones complejas que van más allá de una mera situación en un aquí, involucra especies de espacios que le son inherente a la memoria y al imaginario de ese cuerpo que habita. Habitar se constituye entonces en un medio de relaciones entre lugaridades reales y virtuales que se construyen mediante significaciones.

\section{REFERENCIAS}

Costa, M. (2006). La propuesta de MerleauPonty y el dualismo mente/cuerpo en la tradición filosófica. Revista de filosofía A Parte Rei, (47), 1-7.

DRAE. (2007). Diccionario de La Lengua Española. Real Academia Española. $23^{\mathrm{a}}$ ed. Madrid.

Flores, L. (2003). Fenomenología de la espacialidad en el horizonte de la corporalidad. Teología y vida, 44(2-3), 265-269. Recuperado de http://dx.doi.org/10.4067/ S0049-34492003000200011

Foucault, M. (1984). De los espacios otros. "Des espaces autres" [Conferencia Cercle des études architecturals, 1967]. En, P. Blitstein y T. Lima (Trad.), Architecture, Mouvement, Continuité, (5), 46-49.

Heidegger, M. (1994). Construir, habitar y pensar. [Conferencia Darmstadt, Alemania, 1951]. En, E. Barjau (Trad.), Conferencias y artículos. Barcelona: Serbal. 
Drew, C., Leblanc, M-C. \& Proulx, D. (1972). Louis I. Kahn. Phillips Exeter Academy Library. ARC-6021 - la pensée constructive en architecture. Recuperado de https://www.arc.ulaval.ca/files/arc/ Louis-Kahn_Exeter.pdf

Merleau-Ponty, M. (2000). Fenomenología de la percepción. Barcelona: Península.
Perec, G. (2001). Especies de espacios. Barcelona: Montesinos.

Waldenfels, B. (2004). Habitar corporalmente en el espacio. $\Delta \alpha \iota^{\prime} \mu \omega v$. Revista de Filosofía, (32), 21-37. Recuperado de https://digitum.um.es/jspui/ bitstream/10201/9188/1/Habitar\%20 corporalmente\%20en\%20 el\%20 espacio.pdf 